\section{Natural Position in Childbirth}

SIR,-I was much interested in Dr. Kathleen Vaughan's letter (Jan. 31, p. 222). I have seen women in Persia deliver themselves in the squatting position, walking to the doorway of their hut to do so. Placenta followed baby almost immediately, and there were never any perineal tears. The babies, however, were always small, averaging $5 \frac{1}{2} \mathrm{lb}$. $(2.5 \mathrm{~kg}$.), and with much smaller heads than most English ones.

In practice I have found the best position for the woman is on her back, with plenty of pillows under her shoulders, and the knees well-flexed-in fact the nearest thing to squatting. The women tell me they can use their pains much better than in the lateral position, and indeed it seems natural that it should be so. If one happens to be single-handed it is easier to control the patient, and for doctor and mother to co-operate. I believe this is the French practice.

As regards perineal tears and stretching of the perineum (which can result in much more lasting damage than a simple tear), I am inclined to think that episiotomy is the answer.

I would like to add that I am the mother of four children, my eldest being born when I was 32 . I was never delivered in the "natural" position, but I practised squatting frequently during the last month of pregnancy and during labour. My babies were always born quickly and easily.-I am, etc.,

Frances M. Taylor.

\section{Health of Students}

SIR,- May I comment on some of Dr. John Pemberton's conclusions (March 13, p. 490)? He states that "some 20\% (of stuđents) were found to be suffering from minor anxiety states and depression." He gives as an example of this that they were afraid of failing their examinations, with all that that entails nowadays. Surely, $\mathrm{Sir}$, this is a normal and very temporary state to be in, or does Dr. Pemberton consider it abnormal to be afraid of ploughing an examination? His other example of anxiety state is that $9 \%$ had insomnia (whether permanent or just before examinations is not stated). He uses as a standard an inability to fall asleep after being in bed for one hour. Is this really meant as a scientific standard? I suggest that Dr. Pemberton talks to a junior probationer nurse, who will tell him about patients who "never sleep a wink" yet manage to snore all night.

In the section on orthopaedic defects he claims an incidence of $34 \%$, with $14 \%$ having flat foot. I wonder if Dr. Pemberton realizes that there is a difference between a flat foot and a foot which looks flat but which stands up to playing tennis, Saturday night dances at the Union, Sunday hikes, and other strenuous activities. Those of us with considerable experience of having cases referred to us after routine inspections of school-children and Service men know that this is a common error.

There is claimed to be a $16 \%$ incidence of postural defects of the spine, that is "scoliosis, kyphosis, and lordosis" (sic). Even if I were prepared to believe that such a high incidence of abnormalities was present, I must disagree with his conclusions. $\mathrm{He}$ states, "Most of the orthopaedic abnormalities found were due to lack of muscle tone and physical development, and could perhaps have been prevented by better previous physical education. They emphasize again the value of adequate and easily available facilities for athletics, sports, and gymnastics as a positive contribution to student health." Later he further states, "The frequency of postural and other orthopaedic defects raises the question of the value of compulsory physical education such as has been introduced for freshmen in at least one British university" Has Dr. Pemberton the slightest evidence to support these conclusions? Does he think that gymnasts never suffer from flat foot or postural scoliosis? Has he any proof that exercises have ever prevented or cured these conditions? I am, of course, quite aware that this is a very common but nevertheless erroneous belief, and that in your leading article you state, "Yet even a young person with severe kyphosis and unfit for most sports may overcome his handicap by learning to swim on his back." If a kyphosis is amenable to treatment it is by developing secondary curves above and below the lesion, and surely a breast and not a back stroke would best do this.

Social medicine has been claimed as "a new scientific approach to medicine." Where are Dr. Pemberton's controls ? Has he examined a similar group of non-students to find out how many of them had postural defects or had ever lain awake at night ? Did he discover the relative incidence of postural defects in those students who do and those who do not play games? Is there a significant difference between those who had compulsory physical exercises and games at school and those who did not?

Many medical men have wondered what the exact function of social medicine is. I hope it is not to produce field surveys without any controls. - I am, etc.,

Sheffield.

SiDNEY PAPPWORTH

\section{Intervertebral Disk Lesions}

SiR,-Dr. J. Donaldson Craig and Mr. A. W. LipmannKessel's letter (March 20, p. 570) on this subject is most illuminating. Andrew Taylor Still and, subsequently, the osteopaths have for sixty years suggested that sciatica and many other referred neuralgic pains are "due to joint disturbances." Evidence is gradually accumulating to prove there is more truth and value in the osteopathic theory than has so far been admitted by the orthodox medical profession.

While from the patient's point of view it is probably unimportant where and by whom knowledge is developed, it is only fair, in my opinion, that medical writers should give credit to the author of any theory they propound or elaborate.-I am. etc.,

London, W.1.

George Macdonald.

\section{Diagnosis of Relapsing Fever}

SIR,-With reference to the interesting paper of Drs. R. I. Bodman and I. S. Stewart (Feb. 14, p. 291) the following notes on diagnostic difficulties in sporadic cases of relapsing fever might be of some interest.

Sporadic cases of comparatively rare diseases often present diagnostic difficulties. Four cases of relapsing fever were observed here in the period from May, 1946, to November, 1947. Three ran a typical course, and Spironema recurrentis could easily be found in the blood smears of two, whilst all responded well to neoarsphenamine. The fourth case caused considerable anxiety and was first considered an acute abdominal condition, then typhoid, until his temperature chart and prompt response to a single injection of $0.45 \mathrm{~g}$. of neoarsphenamine disclosed the true nature of his grave condition.

The case history was as follows. A farmer aged 40 was taken ill with high temperature on May 5, 1946. Next day he was admitted to a surgical ward with colicky pain in the right hypogastric region. W.B.C., 15,000 ; B.S.R., $20-40 \mathrm{~mm}$. He was given sulphadiazine orally (28 g.) and his temperature returned to normal. On May 13. seven days after his admission, he was discharged at his own request, only to be readmitted on May 25. Once more his temperature was around $38^{\circ} \mathrm{C}$. $\left(100.4^{\circ} \mathrm{F}\right.$.), which did not subside after another course of sulphadiazine $(30$ g.) and 180,000 units of sodium penicillin. His spleen was enlarged, and he was transferred to the fever department. The Widal was negative, and, as his temperature chart took on a recurrent character with attacks of fever alternating with temperature-free intervals, relapsing fever was suspected. By now, nearly 5 weeks from his first attack, his general condition had become very critical, and without microscopical confirmation $0.45 \mathrm{~g}$ neoarsphenamine was injected. He responded promptly, and his temperature dropped to normal within 24 hours, after which his general condition improved steadily. He was in perfect health when last seen in September, 1947, more than a year after his illness.

-I am, etc.,

Kosice, Czechoslovakia.

I. Friedmann.

\section{Appendicular Dysfunction}

SIR,-Chronic appendicitis or appendicular dysfunction is a difficult condition to diagnose with any degree of certainty. The physical signs are minimal or even absent, excepting perhaps during an exacerbation.

The surgeon has therefore to make a diagnosis from the history and exclusion by investigation of other types of rightsided pain. It was with interest, therefore, that I elicited a physical sign during the examination of a case of abdominal pain and indigestion which pointed quite definitely to the appendix being the cause of a patient's symptoms. The patient 
had been referred to me with a diagnosis of a duodenal ulcer, and on pressure over the appendix the pain was referred to the umbilical region and reproduced the pain of which he was complaining. This clinical finding could be repeated at will.

The mechanism of the sign was apparent at operation, as the appendix contained a large faecolith. distal to which there was a collection of mucus. Pressure on the appendix therefore probably increased intra-appendicular pressure and produced the referred pain already described. It would seem most unlikely that this observation has not already been described in the' voluminous literature regarding appendicular dysfunction. It is, however, not described in Hamilton Bailey's Demonstration of Physical Signs in Clinical Surgery, which is a very comprehensive treatise on this subject.

McBurney's sign is used extensively in the diagnosis of appendicular dysfunction, but the sign described above requires more generalized pressure in the right iliac fossa, and it should be possible to obtain it in any case where the appendix contains fluid in its lumen associated with partial obstruction and complete obstruction. This is a dangerous type of appendicular dysfunction, as perforation and peritonitis are likely to occur should acute infection supervene.-I am, etc.,

Newcastle-upon-Tyne.

F. Denis Hindmarsh.

\section{The Lazy Eye}

SiR,--During the four months that have elapsed since my letter to you concerning defective vision in recruits (Nov. 15. 1947 , p. 796) some forty to fifty boys have been referred every fortnight to the ophthalmic centre which I attend because their vision in one eye is $6 / 12$ or less. In the intervals of refracting them I have read with keen interest the letters that have appeared in your correspondence columns on the school ophthalmic service and the lazy eye.

As a Devonian I was pleased to learn from Dr. Margaret $\mathbf{L}$. Foxwell's letter (Jan. 31, p. 228) that the Devon County Council made all their school-children read the letters on the chart. I was equally delighted to read in Dr. Francis J. Lorriman's letter (March 6, p. 476) that Kent County Council had "a plan." I sensed Mr. S. Black's frustration (Jan. 10, p. 77) at the non-fulfilment of the various recommendations of the committees. I was appropriately horrified at Dr. Mark Bradford's statement (March 6, p. 476) that the health visitor had to do the "eye testing" because the doctor was driven too hard by time and bureaucracy's relentless pressure. I shuddered at the thought of the school medical officers having to do a yearly refraction of every school-child at Mr. Black's behest (Feb. 21, p. 368).

I wondered about the type of " refractive error" which afflicted $70 \%$ of Dr. John Pemberton's Sheffield students and which only required $37 \%$ of them to wear glasses. But I became really angry when I read that one-third of the 150 students had either the wrong spectacles or else none at all (March 13, p. 490). So I went and dug out some figures on the eye defects of recruits. Apparently when they were trying to estimate the number of men who would be wearing spectacles if such were to be permitted on active service in the Boer War, the answer was 5\%. During the 1914-18 war some $4 \%$ of the men in the average division were said to need glasses. The Americans rejected $8 \%$ of their "Draft" for visual defect, and calculated that $4 \%$ needed to wear spectacles. In the recent war the Americans estimated that $6 \%$ of their enlisted men had vision in the one eye of $6 / 18$ and below. Some sample analyses of National Service recruits in the United Kingdom during the winter 1946-7 showed that $8 \%$ had vision of $6 / 18$ in the one eye and below. Approximately $5 \%$ of the whole entry needed spectacles.

Therefore it would seem that though a considerable amount of hard work and good will has gone into the treatment of the ophthalmic conditions of the school-child, the end-results cannot in any way be held to be satisfactory. The hard core of the problem remains for solution-that $10 \%$ of the children need a thorough examination by an ophthalmologist. and that $5 \%$ will need to wear spectacles.

I trust, Sir, that you will regard this letter as fair comment. Admittedly I do not advance any constructive policy; I hope, however, that the scheme that is receiving consideration by the Council of the Faculty of Ophthalmologists will provide a successful solution.-I am, etc.,

Lndon. S.W:1

G. C. Dansey-Browning.

\section{The Department of Medical Photography}

SiR,--In his unusual article entitled "Where are we going ?" Dr. Ff. Roberts (March 13, p. 485) devotes half a column to clinical, or better termed medical, photographic departments. His comments in this connexion rest beneath the curious subtitle "The Fetish of Perpetual Expansion," and it seems unfortunate that of the many examples which could be marshalled to illustrate this section Dr. Roberts has chosen one which lends but little support to many of his arguments.

As one of the authors quoted without context, I would submit that subsequent remarks concerning Pasteur, Thomson. and Hopkins are both facetious and irrelevant. The very extent of quotation in this complete reference seems indicative of a lack of first-hand experience and hence detracts from any conviction apparent in other passages.

By the very nature of their work medical photographic departments are further divorced from the general run of hospital practice than are many of the other special departments : in many instances they are to be found in the medical schools and not in hospitals. It seems only fair to point out that these departments do not exist primarily to ease the burden of the clinician, to conserve manpower, or to show an economic return in the strict sense of the term : the accent is, or should be, placed far more on the record and educational aspects.

As the above comments are not offered in any sense of justification for the existence of medical photographic departments, no further elaboration should be necessary. It would be interesting to know, however, if Dr. Roberts would condescend to use lantern slides and material for publications prepared to meet his own requirements, or if he would prefer to perpetuate cracked and faded slides, and further blur the impression of half-tone blocks monotonously copied from book to book?-I am, etc.,

London, S.W.1.

Peter Hansili.

\section{Alcoholics Anonymous}

SIR,--You have no doubt heard before this of our organization, which, though American in origin, has in the past year commenced activities in Great Britain. We have already had some measure of success and are now enrolling new members every week.

A brief description of our aims and objects appeared in the Lancet last year, and from time to time the daily, Sunday. and weekly Press have had articles about us. We are most anxious, however, to have the approval of the medical profession as a whole, as we consider that without any doubt the best approach to an alcoholic patient is through his or her own doctor.

In recent weeks we have had contacts with many doctors, and not only have we had no adverse word of criticism from them, but several have written to us or telephoned to us in terms of the warmest commendation. In particular they appreciate our help in rehabilitation of the patient after medical treatment. Needless to say we have no patent medicine, nor do we offer any form of medical treatment, though it often falls to our lot on meeting a new patient who asks for our help to recommend that he obtains treatment from his or her own doctor. We claim that our most valuable work lies in showing to the alcoholic who wishes to recover, through our own personal example, that it really is possible to achieve total abstinence and at the same time find an entirely new and completely happy way of living.

Above all we like it to be very plainly understood that we are not a reform society, and we have no interest in alcoholic patients unless they have a genuine desire to stop drinking. We expect them to approach us, or at any rate to express to someone else a desire to hear more of our methods.

I should be most grateful if you would allow me space for this letter, and in particular if you would state that we would welcome enquiries to our monomark address, simply "BM/AAL, London, W.C.1." For your own information. I enclose my name and address as a guarantee of good faith, and regret that our rules compel me to sign this letter, 